\title{
LA RECUPERACIÓN DE UNA TECNOLOGÍA TRADICIONAL: ¿UNA ALTERNATIVA PARA LA AGRICULTURA FAMILIAR? LA ASOCIACIÓN DE PRODUCTORES DE YERBA MATE EN SISTEMA BARBACUÁ DEL CENTRO DE LA PROVINCIA DE MISIONES, ARGENTINA ${ }^{1}$
}

\author{
THE RECOVERING OF A TRADITIONAL TECHNOLOGY: AN \\ ALTERNATIVE FOR FAMILY FARMING? THE ASSOCIATION \\ OF PRODUCERS OF MATE TEA WITH BARBACUA SYSTEM \\ IN THE CENTER OF THE PROVINCE OF MISIONES, \\ ARGENTINA
}

\author{
Pablo Forni \\ Consejo Nacional de Investigaciones Científicas y Técnicas - Buenos Aires - Argentina
}

\begin{abstract}
Por generaciones, la producción y elaboración de yerba mate ha estado primordialmente en manos de miles de productores familiares en la provincia de Misiones (Argentina). Sin embargo, políticas de desregulación, cambios tecnológicos y procesos de concentración económica los han ido relegado a meros proveedores de materia prima a la industria. Este artículo describe y analiza la red socio técnica impulsada por un grupo de productores familiares que buscan recuperar una tecnología tradicional (los secaderos tradicionales o de sistema barbacuá) como alternativa productiva. Se presta atención a la historia del cultivo y elaboración de la yerba mate en el territorio, a las especificidades de este proceso productivo único en el mundo y finalmente al proceso de articulación de la red productiva evaluando sus logros y limitaciones. La perspectiva teórica es la teoría del actor red (ANT).

Palabras-llaves: Desarrollo Regional. Agricultura familiar. Yerba mate. Tecnología tradicional. Teoría del actor red
\end{abstract}

\begin{abstract}
For generations, the production and processing of yerba mate has been primarily in the hands of thousands of family farmers in the province of Misiones (Argentina). However, policies of deregulation, technological changes and processes of economic concentration relegated these farmers to mere suppliers of raw materials to industry. This article describes and analyzes the socio technical network promoted by a group of family farmers seeking to recover a traditional technology (barbacuá drying system) as a productive alternative. Attention is paid to the history of growing and processing of yerba mate in the territory, to the specificities of this unique production process and finally to the process of articulation of the productive network evaluating its achievements and limitations. The theoretical perspective is that of the the actor network theory (ANT).

Keywords: Regional Development. Family agriculture. Mate tea. Traditional technology. Actor network theory.
\end{abstract}

\footnotetext{
${ }^{1}$ IDICSO-CONICET. Este artículo forma parte del Proyecto de Investigación Plurianual del CONICET "Expropiación cognitiva": tensiones en la producción y uso social de conocimientos. Estudio de modalidades emergentes en relación con diferentes tipos de saberes: científicos, tradicionales, informacionales y laborales"
} 


\title{
1 Introdución
}

\begin{abstract}
Arriba, la escena parece arrancada de un sueño. Sobre una altiplanicie de hojas que se pierde en largas penumbras, flotan los vahos blanquecinos de la yerba secada, su perfume bruscamente intolerable. Como sombras de otro mundo armadas de horquillas, se mueven media docena de hombres.. . El sesenta por ciento de la yerba de Misiones se seca de este modo. El resto, en instalaciones mecánicas de secanza rápida. Pero todo el mundo sabe que la yerba de catre o de barbacuá tiene otro sabor... Rodolfo Walsh ("Argentina ya no toma mate", 1966, pp 159)
\end{abstract}

Desde hace casi un siglo la producción y elaboración de yerba mate ha estado primordialmente en mano de miles de productores familiares en el territorio de la provincia de Misiones. Procesos de concentración económica, cambios tecnológicos y políticas de desregulación han ido relegando a estos productores a la condición de meros proveedores de materia prima para las grandes empresas del sector que abarcan casi exclusivamente la elaboración y comercialización del producto. Esto provoca la pérdida de viabilidad económica de las pequeñas explotaciones y el despoblamiento rural por falta de oportunidades productivas y laborales en general. Este artículo describe la iniciativa de un pequeño grupo de jóvenes productores yerbateros por revertir todas estas dinámicas a través de la recuperación y potenciación de una tecnología tradicional que se encontraba casi completamente abandonada: El secadero barbacuá. Con la convicción de que se encontraban en condiciones de producir "la mejor yerba mate" por fuera de las grandes empresas que dominan el sector, llevan adelante acciones conjuntas y relaciones con diferentes organismos pùblicos y otros productores familiares que les permiten ir articulando una red socio técnica muy diferente que les permite mantenerse en la actividad y generar producción y empleo en torno a sus plantaciones y secaderos. El artículo rescata los importantes logros del grupo así como señala los desarrollos incompletos o endebles de esta red socio-técnica en formación.

La estrategia metodológica de la presente investigación es cualitativa. Se realizaron 19 entrevistas a productores, comercializadores e informantes claves entre 2014 y 2015 tanto en la provincia de Misiones como en Buenos Aires. Asimismo, se visitaron chacras, instituciones y varios de los barbacuás de los miembros de la asociación. Estos datos se integran con los provenientes de publicaciones sobre la historia y características de la región así como de la trayectoria y actualidad de la actividad yerbatera en general.

\section{Cuatro siglos de historia: Del té de los jesuitas al oro verde y el tractorazo}

El árbol Ilex Paraguaiensis es originario del bosque atlántico que abarca extensas áreas de Paraguay, Argentina y Brasil. Crece en forma silvestre en las cuencas altas del río Paraná, el río Uruguay y algunos afluentes del Paraguay. El consumo de sus hojas se remonta a los pueblos originarios que recolectaban sus hojas y las utilizaban sobre todo con fines rituales pues tenía un carácter divino para los guaraníes. Estos comerciaban las hojas con regiones de predominio incaico de modo que la su denominación en guaraní devino caá (hierba en guaraní) mate (calabaza utilizada para beber la infusión en quechua). A partir de 1537 los conquistadores españoles se instalan en Asunción y establecen una primera alianza con los guaraníes de los alrededores de los que tomarán el consumo de la yerba mate. Con la organización del virreinato de Perú este consumo se expande a amplias regiones de la América española. A comienzos del siglo XVII la Compañía de Jesús se establece en la región y son miembros de esta 
orden religiosa los que estudian y desarrollan el proceso de germinación de las semillas de yerba mate dando lugar a importantes plantaciones que serían de los pilares de su economía. Los jesuitas contaban con entre diez y treinta hectáreas de yerbales plantados en cada pueblo que proveían al consumo de los sus habitantes así como al comercio con Buenos Aires, el alto Perú y otras regiones del dominio español. (López, 1974) Con su expulsión en 1767 se pierde el conocimiento necesario para su cultivo y paulatinamente desaparecen las plantaciones existentes. En la década del treinta del siglo XIX se da un intento efímero de recuperar el cultivo de la yerba de la mano del naturalista francés Aimée Goujard, mejor conocido como Bonpland, bajo la protección del caudillo entrerriano Francisco Ramírez. Sin embargo, al poco tiempo las autoridades paraguayas destruyen los yerbales remanentes del período jesuita y deportan al cientìfico al interior de Paraguay. Durante el resto del siglo XIX solamente se explotan los yerbales silvestres existentes en la región primero bajo monopolio estatal paraguayo y luego de la guerra de la triple alianza principalmente por parte de empresarios brasileños. Es recién a comienzos del siglo pasado que científicos y agricultores redescubren las técnicas para la germinación y cultivo de las semillas de yerba mate olvidadas por más de un siglo. En la provincia de Misiones, sin embargo, será a partir de la década del veinte que comenzarán a multiplicarse las plantaciones y la producción al impulso de una política pública de colonización. (Larguía, 2006; Gortari A)

En 1926, por decreto del presidente Marcelo T. de Alvear, la Dirección Nacional de Tierras establece como condición para la adjudicación de lotes en el territorio de Misiones la obligatoriedad de residir en la explotación así como de implantar entre un $25 \%$ y un $50 \%$ de su superficie con yerbales en un plazo máximo de dos años a partir de la entrega del título provisorio. De acuerdo a la misma normativa, aquellos adjudicatarios que implanten con yerba mate el $75 \%$ de la superficie quedaban eximidos de la obligación de residir pero pagarían un recargo en el precio de la tierra. La resultante de esta política pública es un proceso de ocupación del territorio por parte de inmigrantes preponderantemente de origen europeo para los que la ilex paraguayensis deviene un cultivo central (Cafferata, De Santos y Tesoriero, 1974; Bolsi, 1980; 1986)

La rápida expansión de las plantaciones así como la persistencia de grandes importaciones desde Brasil producen una severa crisis de rentabilidad por la baja del precio de la materia prima que provoca crecientes protestas y malestar entre los colonos. La respuesta gubernamental será la creación de una Comisión Reguladora de la Yerba Mate (CRYM) en el año 1935 con atribuciones para prohibir o autorizar nuevas plantaciones así como de establecer cupos de cosecha. Un año después se creó el mercado consignatario que garantiza un precio sostén para el producto. Más allá de distintas maniobras y conflictos de intereses, el sistema regulatorio así constituido permitió sustituir las importaciones desde el Brasil y satisfacer la expansión del mercado interno. También reguló la disputa entre los productores primarios y el resto de la cadena de valor en el contexto de mantener a la yerba mate como un producto de consumo masivo y precios bajos.

Sin embargo, todo esto cambió a partir de 1991 cuando las políticas desregulatorias de la época pondrían fin a 56 años de regulaciones. En efecto, el Decreto $\mathrm{N}^{\circ}$ 2284/91 del Poder Ejecutivo Nacional disuelve al CRYM permitiendo la libre implantación de yerba. A partir de entonces aumenta progresivamente tanto la superficie implantada como la producción total. Durante los primeros años de la desregulación los precios de la materia prima se mantienen relativamente estables debido a cierta escasez inicial y a ventas al mercado brasileño pero a partir de 1997 se desploman los precios de la "hoja verde" y la "hoja canchada" mientras que se incrementa el precio de la yerba mate elaborada. Esto resultó en un incremento de las ganancias de las empresas 
molineras y comercializadoras en desmedro de los productores. La desregulación resulta en la aceleración del proceso de concentración de las ganancias en aquellos que elaboran y comercializan la yerba mate, descapitalizando crecientemente a los productores primarios. En 1998 ocho empresas y tres cooperativas representaban más del $70 \%$ del mercado, solamente las tres empresas más grandes (Las Marías, Molinos Río de la Plata y Mate Larangeira Méndez) controlaban el 50\% del mercado. (Gortari, 2007c)

El agravamiento de la situación de los productores resultó en un malestar creciente y un ciclo de acción colectiva impulsada por diferentes organizaciones de productores. Entre 2001 y 2002 se producen distintas movilizaciones que provocan la intervención del Congreso de la Nación a fin de volver a regular el sector. En junio de 2001 cientos de productores y trabajadores rurales confluyen desde diferentes localidades de la provincia hacia la plaza central de la ciudad de Posadas donde acampan por cincuenta días frente a la casa de gobierno. Los viejos y desvencijados tractores que traen desde las chacras harán que se denomine a estas protesta como el "tractorazo". Finalmente consiguen que el gobernador les garantice un precio mínimo para la materia prima (hoja verde).

El tractorazo no tiene demasiadas implicaciones económicas pero sí en términos gremiales y políticos. Es así que en febrero de 2002 se sanciona la ley que crea el INYM (Instituto Nacional de la Yerba Mate) que es como una recreación del CRYM. Este ya no limita las nuevas plantaciones pero si interviene en el mercado de materia prima incrementando en un $500 \%$ en su primer año de funcionamiento el valor de la hoja verde y la hoja canchada. A partir de entonces, la actividad yerbatera se ha recuperado notablemente. (Rozenfeld y Martínez, 2013; Gortari, 2007b)

El particular proceso de colonización agrícola resultó en una estructura productiva basada en miles de pequeñas y medianas explotaciones familiares que alimentan a un complejo agroindustrial de elaboradores y comercializadores de carácter oligopsónico. En la actualidad aproximadamente 17.000 productores primarios de los cuales el $80 \%$ tiene una superficie plantada igual o menor a las 10 hectáreas, proveen a poco más de un centenar de industrias elaboradoras, de las cuales las cuatro más importantes concentran cerca del $50 \%$ de la elaboración para el consumo mientras que las diez más importantes concentran el $80 \%$ de las ventas del producto final. (Gortari, 2007b; Rau, 2009) 


\section{De la semilla al molino: El proceso productivo}

Tomar mate es una práctica generalizada y cotidiana en una amplia zona de Sudamérica, sin embargo el extenso y elaborado proceso productivo que va de la germinación de la semilla al producto elaborado es poco conocido. Tal como se describe en la sección anterior, el mismo fue desarrollado en las reducciones jesuíticas cuatro siglos atrás y continúa sin grandes innovaciones hasta el presente. En lo que sigue se describe de modo resumido y esquemàtico este proceso de años. Tal descripción es necesaria para entender el rol e importancia de diferentes actores de la red socio-técnica considerada.

La germinación de las semillas es lenta y los plantines son llevados al campo luego de varios meses en el vivero, A partir de la implantación, se debe aguardar entre dos y cuatro años para poder realizar las primeras podas a los árboles. El máximo rendimiento se alcanza recién entre el séptimo y el octavo año, extendiéndose la vida útil del yerbal durante décadas. Existen, por ejemplo, yerbales de más de medio siglo que siguen en plena producción. Las plantaciones de yerba demandan trabajos de desmalezamiento más o menos constantes a lo largo de todo el año para evitar que crezcan otras plantas que compitan con las de yerba mate. La cosecha se realiza a lo largo de los meses que van de abril a septiembre, consistiendo básicamente de una o varias podas realizadas por trabajadores cosecheros o "tareferos" como se los denomina en la región. Históricamente estos últimos son trabajadores estacionales con bajas remuneraciones y pésimas condiciones de trabajo. La crisis de la yerba en los años noventa no hizo sino agravar esta situación al desatar el éxodo de muchos de estos trabajadores de las colonias a barriadas obreras periurbanas en las ciudades intermedias de la provincia de Misiones. (Rau, 2005) En años recientes, diferentes políticas públicas y fundamentalmente el accionar del RENATEA (Registro Nacional de Trabajadores Rurales de la Argentina) han comenzado a regularizar la situación laboral y mejorar las condiciones de trabajo en esta actividad.

La transformación de la hoja cosechada combina procedimientos que son fundamentalmente los mismos desde tiempos precolombinos. El objetivo de los mismos es detener los procesos biológicos de degradación de los tejidos del vegetal a través de su casi total deshidratación. El agente transmisor de calor es la combustión de biomasa. El sapecado es un primer golpe de calor que detiene los procesos enzimáticos y rompe las vesículas de agua en las hojas a una temperatura aproximada de $120^{\circ}$ centígrados. El secado propiamente dicho consiste en exponer las hojas a temperaturas de entre $70^{\circ} \mathrm{y}$ $120^{\circ}$ según el sistema elegido a fin de disminuir la humedad de las mismas del 10/15\% al $1 / 3 \%$. Esto se hace por sistema tradicional o barbacuás, al que nos referiremos más adelante o usualmente en secaderos mecánicos con cintas o tubos transportadores que completan esta etapa en aproximadamente una hora o menos. A esto sigue el canchado que es una molienda grosera en trozos que no excedan $1 \mathrm{~cm}^{2}$ a fin de disminuir el volumen a ser estacionado. La yerba se estaciona en bolsas de arpillera o propileno de $50 \mathrm{~kg}$ o bien a granel en galpones de madera denominados "noques". El uso de la madera así como de carpetas aislantes es a fin de prevenir el ingreso de humedad al galpón. El clima de la región es extremadamente húmedo con grandes cambios de temperatura. El estacionamiento puede ser natural o acelerado. El natural demanda entre uno y dos años mientras que el acelerado de 30 a 60 días. El propósito es que por procesos de transformación espontánea la yerba adquiera las características de sabor y color adecuadas para el consumo. Finalmente la molienda implica sucesivas operaciones de clasificación, trituración y mezcla para su posterior envasado en paquetes de medio o un kilogramo y comercialización. (Gortari b, pp 328-332) 


\section{EI sistema barbacuá}

La palabra barbacuá es poco y nada conocido fuera de la región productora. Sólo recientemente comienza a aparecer escrito en algunos paquetes de yerba comercializados. Sin embargo es ampliamente utilizado en las áreas de producción desde hace siglos. Se proponen dos etimologías para esta palabra. Para algunos es una corrupción fonética de la voz guaraní m barambacuá, cuyo desglose es el siguiente: Mba: todo, montón o 0Mä: montón, manojo, Ra: Eufonía, enlace que brinda a la palabra sonoridad agradable, Mbacuá: cosa tostada o dorada: Literalmente: Montón o manojo de cosas tostadas o doradas. En cambio, para otros se trata simplemente de una deformación del barbacoa de origen caribeño que alude a una parrilla de palos similar a los primitivos barbacuás. (Vidal de Battini, 1953; Ricca, 2009)

Los primero secaderos hechos por los colonos eran en efecto estructuras rústicas hechas de palos con forma de bote invertido sobre la que se secaban unos 5000 kilos de hoja verde. Los múltiples incendios y la ineficiencia de estos dispositivos llevaron a construir barbacuás de ladrillo y madera techados. Ningún barbacuá es idéntico a otro, cada uno ha sido hecho de modo artesanal por una o varias familias de productores usando en muchas ocasiones ladrillos fabricados en el mismo lugar o muy cerca. Refacciones y reconstrucciones muchas veces debido a incendios y ampliaciones hacen que los mismos vayan siendo modificados con el paso de los años. Sin embargo, todos responden aproximadamente a un diseño básico que una publicación del Ministerio de Agricultura publicaba a comienzo de la década del setenta y que aún hoy es ampliamente reproducida. (Ministerio de Agricultura, 1971) 
Gráfico 1. Antiguo barbacuá de palos o tarijo durante los primeros años de la colonización. Pueden apreciarse los sables de madera utilizado para el zapecado que sostienen los cuatro hombres de pie a la izquierda del barbacuá.

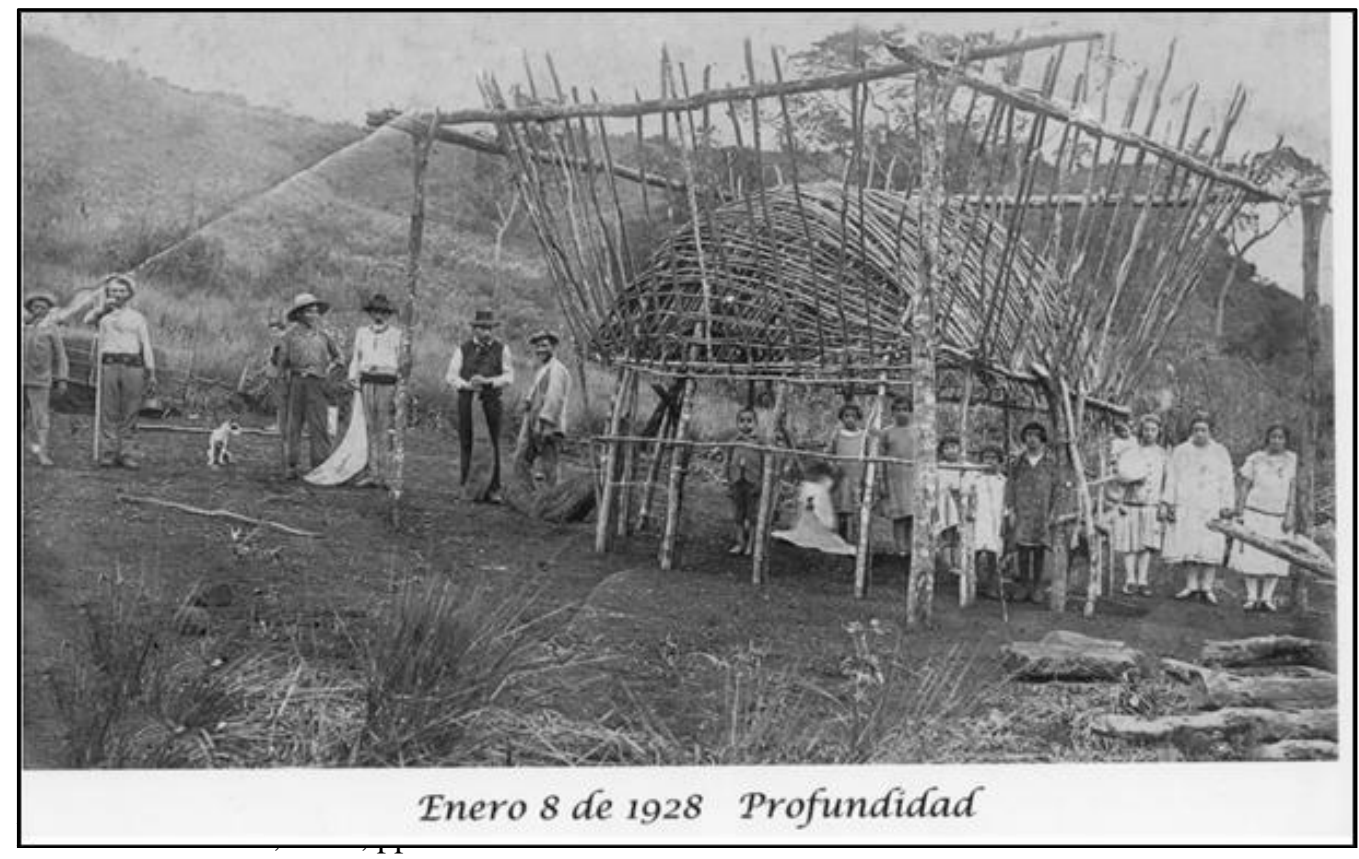

El barbacuá consiste típicamente de una parrilla circular o elíptica de unos 7 metros de diámetro aproximadamente construida con varillas de madera en forma de una gran cúpula sostenida perimetralmente por columnas (tambos) de 1,20 a 1,80 metros de altura y rodeado de una barandilla a fin de evitar el deslizamiento de la carga de hojas. A unos 12 metros del centro se encuentra una hornalla que se comunica con el centro de la parrilla a través de un túnel que se inicia con un diámetro de más o menos un metro y termina con unos $60 \mathrm{~cm}$ a la salida, debajo de la cúpula de madera, en forma de una chimenea que cuenta con una campana protectora contra chispas. La totalidad de la instalación se encuentra en el interior de una construcción de madera o ladrillos a fin de conservar el calor.

En el funcionamiento del barbacuá es clave la figura del maestro secador o "urú" con un saber empírico basado en la experiencia y su sentidos de la vista, el olfato y el tacto. Este extiende las hojas "sapecadas" sobre la canasta de madera en capas de 30 a $40 \mathrm{~cm}$ donde son expuestas a una temperatura de entre 80 y 100 grados desde abajo. En la parte superior de la canasta las temperaturas oscilan entre 60 y 70 grados. Cuando la capa de hojas comienza a secarse va adquiriendo una consistencia quebradiza, el "urú" va removiendo con una horquilla y recostando las hojas sobre la barandilla lateral para extender otra capa de hojas y así hasta colmar la capacidad del barbacuá. El determina a lo largo del proceso cuando hace falta más leña y de qué tipo así como en qué momento apagar el fuego. El urú se guía por el aroma, el color y la textura de las hojas Una vez seca, la yerba se enfría lentamente llevando toda la operación 24 horas o más bajo constante supervisión. Cabe aclarar que el trabajo del urú históricamente ha sido considerado insalubre debido a las altas temperaturas de la canasta del barbacuá dónde debe permanecer durante el proceso de carga del barbacuá.

Gráfico 2. Plano de un barbacuá arquetípico según una publicación oficial de la Comisión reguladora de la producción y comercio de la yerba mate del año 1971.

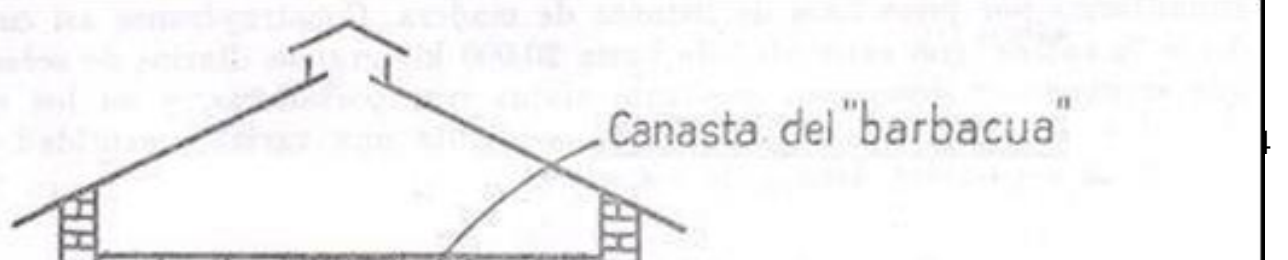


Fuente: $<$ http://elmuseodelmate.com.ar/index.php?option=com_content $\&$ view=article\&id=56:origen-dela-yerbamate \&catid=34:articulos\&Itemid=53>.

\section{El así llamado proceso de traducción de la teoría del actor red}

A partir de una aproximación inductiva el concepto de red fue utilizado para orientar las indagaciones entre los diferentes actores presentes en la producción, elaboración y comercialización de yerba mate orgánica y artesanal. Al interior de este universo, la experiencia de la asociación de productores en sistema barbacuá es abordada específicamente desde la teoría del actor red (Action Network Theory o simplemente $A N T$ por las tres iniciales en inglés) debido al papel central que desempeña una clase de componente no humano, los secaderos del tipo barbacuá, en un proceso de innovación tecnológica y social a la vez. (Latour, 1987, 2008; Law, 1986) Cabe aclarar que esta perspectiva teórica brinda conceptos sensibilizadores para abordar la investigación empírica y no enunciados apriorísticos sobre los fenómenos en cuestión. (Bueger y Stockbruegger, 6) La ANT parte de tres principios: El agnosticismo apunta a la imparcialidad analítica a la hora de considerar a los actores sin distinción de su naturaleza humana o de aspectos sociales o técnicos. La simetría generalizada, por su parte, alude a dar cuenta de las perspectivas divergentes o conflictivas de los diferentes actores en la red analizada. Por último, el principio de asociación libre demanda que no haya distinciones a priori entre lo tecnológico o natural y lo humano. (Callon, 1986a; Singleton y Michaels, 1993) Esta perspectiva teórica enfatiza la heterogeneidad del mundo social, la distribución de propiedades de agencia a través de la divisoria humano/no humano y los procesos a través de los cuáles las redes socio técnicas se extienden a sí mismas. (Shiga, 2007)

En concordancia con este marco conceptual, se presta atención al carácter heterogéneo de la red socio técnica incluyendo individuos (funcionarios de distintas agencias gubernamentales, productores y sus familias, comercializadores), grupos que registran distintos niveles de formalización y artefactos como los secaderos barbacuas entre otros. Estos artefactos obviamente han sido y son construidos y modificados por individuos o generaciones de individuos de una misma familia, pero una vez en funcionamiento devienen influyentes en la reconstrucción de la red. Es decir, los barbacuas redefinen la red socio técnica de producción de yerba mate al permitir el ingreso de nuevos actores tales como pequeños productores o consumidores que buscan 
productos artesanales, modifica el posicionamiento de los que ya formaban parte de esta y excluye a otros (grandes acopiadores o empresas dominantes del sector). (Celis y Forni, 2008)

Complementario de lo anterior es la perspectiva de la sociología de la traducción tal como lo plantea la misma ANT. (Callon, 1986b; Law, 1992; Daza Villadiego, 2012) Traducción alude a cómo los actores construyen significaciones comunes, definen representatividades e intentan cooptarse unos a otros y lograr acuerdos en pos de intereses tanto individuales como colectivos. En este proceso que no es otra cosa que la conformación de la red socio técnica, pueden diferenciarse cuatro etapas sucesivas: problematización, interesamiento enrolamiento y movilización. Estas categorías analíticas son empleadas en el análisis del proceso dinámico de constitución de la red de productores de yerba mate en sistema barbacuá de la zona de Oberá en la provincia de Misiones.

En un momento inicial, distintos actores pueden estar involucrados en diferentes procesos de traducción con resultados diversos. Algunos productores han abandonado los barbacuas familiares y venden la materia prima directamente a acopiadores, otros en cambio se esfuerzan por mantener los suyos en funcionamiento e incluso alguno intenta comercializar su producción con una marca propia. Durante la primera etapa, la problematización, ciertos actores buscan definir las identidades e intereses de otros actores de modo que sean consistentes con los propios. Asimismo, despliegan estrategias a fin de persuadir a todos de la validez de su definición del problema así como de sus posible vía de solución. Los ingenieros del INTA estaban convencidos de que la recuperación de los barbacuas era el camino para revitalizar a los productores familiares y evitar el despoblamiento de las colonias. De este modo, los hasta ese momento considerados obsoletos, despreciados o directamente abandonados artefactos que yacían en sus chacras se convertirán para los productores, distintas agencias gubernamentales, autoridades provinciales e incluso eventualmente consumidores en centros urbanos distantes en el "punto de pasaje obligatorio". (Callon b) De este modo, el concepto de traducción posee una doble acepción: de cambio o adaptación de significados y de cambio de lugar o situación.

La segunda etapa, el interesamiento (intéressement) involucra las múltiples acciones a través de las cuales un actor intenta convencer a otros actores de manera que acepten la traducción que propone. Aquí también se produce una doble traducción pues es necesario hacerse comprensible para hacerse de aliados y asimismo se produce un proceso más amplio de traducción (en el sentido de cambio de significado y movilización) respecto de la situación inicial. Los ingenieros del INTA obtienen recursos de un proyecto de esta institución gubernamental y durante más de un año visitan a muchos productores propietarios de barbacuás ya sea en funcionamiento o en desuso, sostienen reuniones, encuentros a fin de convencerlos de la conveniencia de articular una estrategia productiva en torno a estos barbacuás. En la búsqueda de aliados, se van enfocando en la generación más joven que está interesada en encontrar una alternativa productiva que les permita sostener la producción de sus chacras y no tener que emigrar a algún centro urbano.

La tercera etapa o enrolamiento (enrôlement) alude a la definición y coordinación de roles específicos a partir de la traducción que se impone en la red en formación. El enrolamiento es exitoso en la medida en que los actores enrolados van asumiendo los roles que se les plantearon durante el interesamiento. Los productores que vienen participando de los encuentros y otras actividades con los ingenieros del INTA proceden a crear la Asociación de productores de yerba mate en sistema barbacuá definiendo puestos y responsabilidades en la asociación civil. Una segunda fase de 
enrolamiento es la constitución legal de una cooperativa que posibilite comercializar una marca colectiva propia de la asociación. A mediados de 2015 este trámite se encuentra inconcluso.

Por último, la movilización (mobilisation) abarca los diferentes y sucesivos movimientos necesarios para lograr que la red comience a trabajar. Esta etapa se caracteriza por diferentes alianzas con actores que cuentan con habilidades específicas tales como el equipo de energía del INTI (Instituto Nacional de Tecnología Industrial) que hace un asesoramiento para mejorar el funcionamiento de los barbacuás. Otros actores con los que se busca establecer alianzas son funcionarios y organismos provinciales ya sea para brindar asesoramiento o, sobre todo, recursos financieros para iniciar la producción. El mismo gobernador de la provincia de Misiones brinda apoyo político y legitimidad a la asociación en más de un acto público en los que habla de las bondades de los barbacuás.

\section{La red socio técnica}

El proceso de traducción emprendido por los ingenieros del INTA implica recrear la red productiva que hace posible la elaboración y comercialización de la yerba mate. Reintroducir y mejorar al secadero barbacuá encierra el propósito de convertir a los colonos que han heredado estos artefactos de generaciones pasadas de sus familias en portadores de una tecnología y habilidades únicas. De proveedores de materia prima que es a los que los lleva inexorablemente la lógica de la concentración del sector, devienen productores de un producto "premium" con características únicas y renovadas oportunidades de comercialización a precios superiores. Siendo coherentes con la perspectiva teórica asumida, a continuación se ofrece en forma esquemática el detalle de los integrantes de la red socio-técnica. Asimismo, se señalan posibles componentes faltantes o débilmente articulados a la misma hasta el momento (mediados del 2015).

\section{Los Yerbales de las colonias de la sierra central}

Tal como reseñamos, los secretos de la domesticación del Ilex paraguayensis fueron descubiertos cuatro siglos atrás por los misioneros jesuitas y redescubiertos hace 100 años. Los yerbales de la sierra central de la provincia de Misiones se remontan al período del "oro verde" y la llegada de colonos de diversas procedencias durante la década del veinte. Los productores que integran la asociación cuentan con los yerbales familiares en producción y además con la posibilidad de integrar al proceso la producción de yerbales de vecinos de cada uno. En efecto, las colonias presentan pequeños yerbales en muchos casos de baja productividad debido a su antigüedad. Los colonos que los poseen ven dificultada la posibilidad de comercializar la materia prima que producen debido a lo reducido de su producción y en algunos casos a la carencia de vehículos adecuados para sacarlos de la colonia y llevarlos a los centros de acopio. De hecho, la recuperación de los barbacuás permite reactivar la producción de numerosos pequeños yerbales ubicados en sus cercanías.

\section{Los Secaderos de tipo barbacuá}

El período de expansión inicial de la yerba mate se ve signado por la multiplicación de los barbacuás en todas las zonas donde se implanta la yerba mate. Sin embargo, ya a comienzos de los años setenta una publicación especializada los consideraba instalaciones "primitivas". (Comisión Reguladora, 1971) En efecto, a partir de entonces comienza a generalizarse el uso de secaderos industriales que a través de cintas transportadoras y la inyección de aire caliente pueden secar enormes cantidades 
de yerba mate en un tiempo muchísimo más breve y empleando a la misma cantidad de personal. Los barbacuás son progresivamente abandonados por los pequeños y medianos productores que los habían construido y utilizado por al menos dos generaciones.

En 1976 funcionaban en el departamento de Oberá 185 secaderos de yerba mate de tipo barbacuá, en 1989 ya eran 94 y en 2013 sólo 16 en este departamento y 62 en toda la provincia. El abandono de los barbacuás por un lado relega a los productores pequeños y medianos en la cadena de valor dejándolos solamente como proveedores de materia prima al sector industrializador y comercializador. Por otro, colabora con el progresivo despoblamiento de las colonias al eliminar fuentes de trabajo y dejar fuera del circuito productivo a agricultores con producciones muy pequeñas.

La marcada concentración de la actividad yerbatera potenciada por la desregulación de los años noventa confinaron a los pequeños y medianos productores al lugar de proveedores de materia prima (hoja verde) a las grandes empresas industriales (secaderos y molinos) los que a su vez ubican en los canales de comercialización (distribuidoras e hipermercados) la yerba mate ya elaborada y envasada. Este lugar acotado en la red productiva minimiza las ganancias de estos agricultores tornando poco viable el sostenimiento de los yerbales que sus familias vienen cultivando desde hace décadas. La resultante es el abandono de la actividad y el desplazamiento de los jóvenes a centros urbanos en busca de empleos usualmente de baja calificación. El abandono tanto de los barbacuás como de las pequeñas plantaciones de yerba mate lleva al progresivo despoblamiento de las colonias.

La capacidad instalada de los barbacuás que integran la asociación es de aproximadamente $3.700 .000 \mathrm{~kg}$ de yerba mate canchada. En 2015 se procesa efectivamente un millón de $\mathrm{kg}$ de los cuales se envasa con las doce marcas propias unos $500.000 \mathrm{~kg}$ o sea el $50 \%$. Cabe señalar que existen diferencias de capacidad entre los barbacuás, los más grande pueden procesar unos $15.000 \mathrm{~kg}$ por día mientras que los más pequeños aproximadamente la mitad de esa cantidad. Los secaderos "de cinta" industriales tienen la capacidad de procesar diez veces tales cantidades (entre $60.000 \mathrm{y}$ $150.000 \mathrm{~kg}$ ) por día empleando la misma cantidad de personas.

Gráfico 3. Barbacuá recuperado en la localidad de Guaraní, Oberá. Al centro puede observarse leña en la boca del foso de la hornalla y a la derecha la puerta de acceso a la canasta.

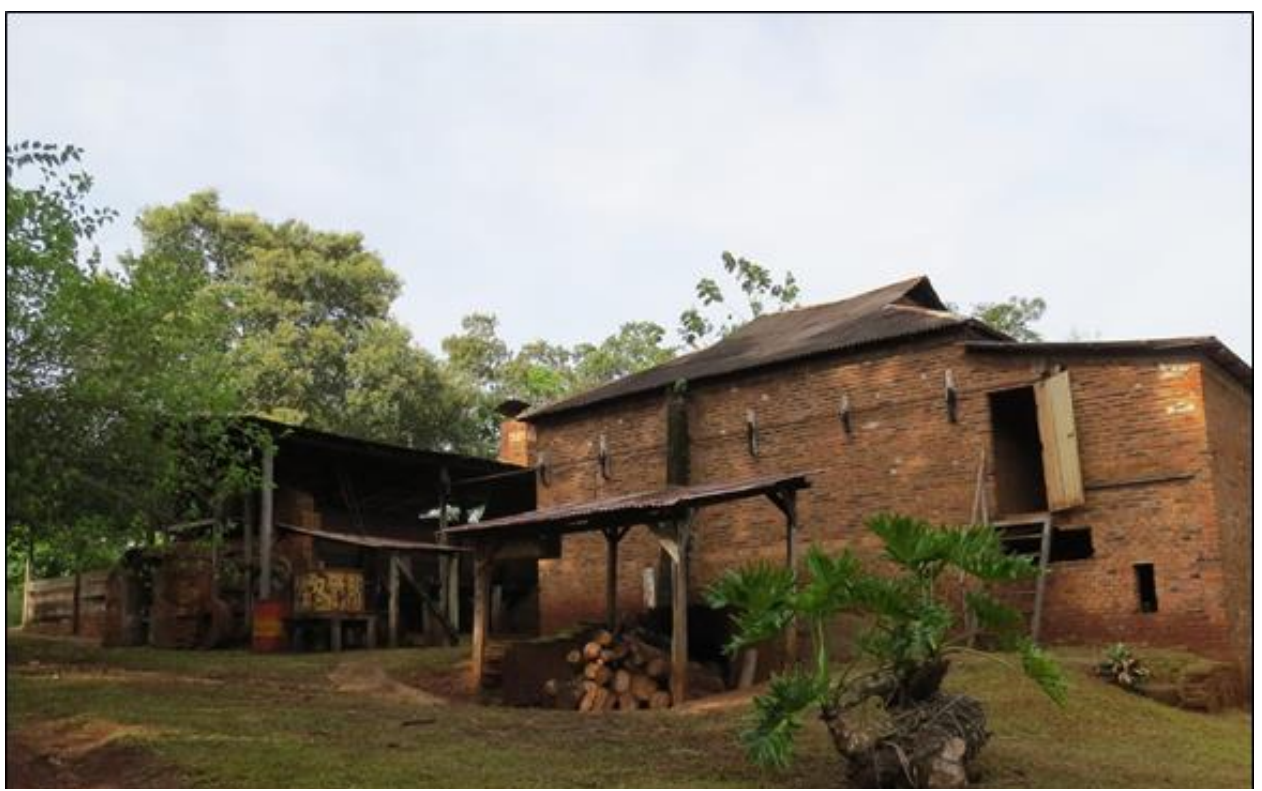


Fuente: Foto propia, Febrero de 2015.

\section{Los noques}

Se trata de artefactos tan importantes como los mismos barbacuas para la constitución de la red socio técnica. Es en estos edificios especialmente acondicionados dónde la yerba canchada es estacionada para proseguir su proceso de maduración, perder gradualmente su clorofila y cambiar su tonalidad. Un aspecto crucial de esta red es tornar el proceso de producción de la yerba mate de continuo a discontinuo extendiéndose de unas pocas semanas a entre uno y dos años. El término noque alude a los sacos de cuero en los que antiguamente se hacía el estacionamiento de la yerba canchada. (Vidal de Battini). Los depósitos o noques como se los conoce en la zona deben asegurar que la yerba se madure lentamente a lo largo de muchos meses más allá del clima extremadamente húmedo de la región así como de los cambios bruscos de temperatura. Para esto suelen estar separados del suelo y estar construidos en madera utilizando en muchos casos carpetas aislantes. Algunos productores utilizan bolsas de cincuenta kilos mientras que otros prefieren estacionar la yerba "a granel" en estos depósitos. Al igual de lo que sucede con los barbacuás, no hay dos noques iguales en lo que respecta a forma y dimensiones. Se encuentran siempre próximos a los barbacuás y en su interior se encuentran también los implementos para el envasado en bolsas de papel de un kilo o medio kilo, ya sea mecánico con maquinarias pequeñas o directamente manual con sólo una balanza y una cuchara. Mantener la yerba estacionada tanto tiempo insume un fuerte costo financiero para los productores de la asociación, pues deben esperar prácticamente dos años para percibir ingresos por su producción. Distintos informantes claves y expertos consideran que es en estos noques dónde la yerba mate adquiere características definitivamente superiores a la de la yerba mate de proceso continuo.

\section{Los ingenieros agrónomos del INTA}

A comienzos de 2010 un proyecto impulsado por dos ingenieros agrónomos del INTA (Instituto Nacional de Tecnología Agropecuaria) se propone el "Rescate y Valorización de la Yerba Mate producida por pequeños productores de la zona centro de Misiones en secaderos tipo barbacuá como un producto diferenciado". Eran objetivos del mismo contribuir al desarrollo económico, social, cultural, ambiental y humano de medio centenar de familias de pequeños productores de yerba mate en tres municipios pertenecientes al Departamento de Oberá: Los Helechos, Ameghino y Guaraní. El diagnóstico del que se partía era que en la zona existían muchos barbacuás que habían sido abandonados hacía muchos años, otros recientemente y unos pocos que funcionaban adecuadamente vendiendo su producción ya sea con marca propia o proveyendo a otros. El proyecto se proponía rescatar una forma tradicional de producción de yerba que se encontraba en vías de desaparición a través de la elaboración y comercialización de un producto diferenciado de mayor calidad para el que se percibía que existía un gran mercado potencial. El funcionamiento de los barbacuás aportaría a la persistencia de numerosas explotaciones familiares tanto de los dueños de los mismos como la de muchos de sus vecinos con producciones demasiado reducidas como para acceder a los grandes acopiadores. Asimismo, generaría puestos de trabajo en cada localidad pues el funcionamiento de los barbacuás demanda al menos dos o tres trabajadores durante los meses de cosecha.

\section{Los miembros de la Asociación de Productores}


En el comienzo se organizaron encuentros a los que se invitaba a diferentes productores que tenían o habían tenido barbacuás en funcionamiento. Dadas las características de estas explotaciones familiares, a las reuniones asistían tanto padres como hijos siendo estos últimos los más entusiastas con la idea de recuperar y potenciar a los barbacuás como alternativa productiva. La generación de los padres guardaba ingratos recuerdos de cooperativas fallidas así como de las graves crisis que atravesó el sector yerbatero en las últimas décadas. Era por tanto mucho más escéptico en relación a las posibilidades de recuperar los barbacuás y potenciar la producción de sus chacras. Se realizaron muchos encuentros en los que cada uno, padres e hijos, fue exponiendo su punto de vista mientras se discutían alternativas de acción. El mayor entusiasmo y optimismo de los más jóvenes se vinculaba a la esperanza de encontrar una alternativa productiva viable que les permitiera permanecer trabajando en las chacras sin tener que emigrar a los centros urbanos. Gradualmente los mayores fueron dejando el protagonismo a la nueva generación.

Luego de casi dos años de reuniones y encuentros periódicos se logra conformar un grupo de unos 18 productores de entre 30 y 40 años aproximadamente que de no conocerse previamente pasan gradualmente a desarrollar vínculos de confianza entre sí, siempre con el liderazgo de los ingenieros del INTA, proveniente de una familia de productores de yerba mate y de mayor edad que todos ellos. Ciertamente, todos comparten el mismo sustrato socio-cultural propio de los colonos de la sierra central misionera y concomitantemente dos o tres generaciones consecutivas dedicadas a la yerba mate. Los miembros de la asociación son homogéneos en cuanto a su rango de edad, género y ocupación, no lo son necesariamente en cuanto a la superficie implantada con yerbales, su nivel de capitalización y el tamaño y condición inicial de sus respectivos barbacuás. Catorce de los barbacuás se encontraban en funcionamiento y cuatro inutilizados por el abandono y falta de mantenimiento. Este grupo crea la asociación civil "Asociación de Productores de yerba mate en sistema Barbacuá" siendo elegidos como presidente, vicepresidente y secretario productores que tenían sus secaderos en funcionamiento y comercializaban marcas propias.

La primera acción fue solicitar al gobierno provincial fondos para una prefinanciación de la cosecha. Cómo eran necesarios un mínimo de cincuenta productores se incorporó a la solicitud a aquellos que proveían hoja verde a los barbacuás llegándose a los sesenta y dos productores. Este crédito como otros fue devuelto en tiempo y forma. A partir de aquí el foco de la asociación se puso en la recuperación y mejoramiento de los barbacuás de los socios. Con este fin se obtuvieron otros créditos del Estado provincial. La recuperación implicó trabajos de reconstrucción de barbacuás abandonados desde hacía años que fueron completados fundamentalmente por los mismos productores. Los miembros de la asociación decidieron de común acuerdo destinar en primer lugar el dinero para la restauración de un barbacuá que se encontraba inutilizado por muchos años de abandono y cuyo dueño no contaba con los recursos para ponerlo a funcionar. Posteriormente, fueron siendo mejorados los barbacuás de otros miembros.

Diferentes organismos gubernamentales (INTA, INTI, Gobierno provincial)

En el proceso de articulación de la red, la Asociación de productores fue logrando el apoyo de diferentes agencias gubernamentales. Los aportes de las mismas fueron de orden monetario (crediticio), técnico y de legitimidad. Todos fueron oportunamente necesarios para articular y poner a trabajar a la red. El reclutamiento de 
estos actores es posible gracias a las acciones de los ingenieros del INTA que impulsan el proceso de traducción centrado en los barbacuás y su revalorización. ${ }^{2}$

La asociación recibió créditos de prefinanciación de cosecha del gobierno provincial a través del Ministerio del Agro y la Producción y del Instituto del Fomento agropecuario. Los mismos fueron pagados en tiempo y forma. Asimismo, recibió un subsidio del gobierno provincial para la reparación de barbacuás.

Durante 2014 el Área de Energía del INTI (Instituto Nacional de Tecnología Industrial) realizó una asistencia técnica a la Asociación gracias a las gestiones y una financiación del Ministerio del Agro provincial. El objetivo de la misma fue realizar modificaciones a los secaderos y temperaturas de secado a fin de aportar a la estandarización de los procesos sin que el producto deje de ser elaborado de modo artesanal. Otra innovación relevante tuvo que ver con la inclusión de "trampas de humo" que permiten disipar el humo de la combustión inicial graduando así la exposición de la yerba al mismo. Asimismo, a través del INTA la Asociación pudo desarrollar vínculos con otras instituciones. En este sentido, estableció convenios con la Facultad de Ciencias Forestales de la Universidad Nacional de Misiones para implantación de especies nativas para abastecer de leña a os barbacuás.

El 19 de Abril de 2013 el gobernador de la provincia de Misiones re inauguró en un acto público dos secaderos de tipo barbacuá de sendos miembros de la asociación que llevaban cerrados 8 años uno y 12 años el otro en el Municipio de Guaraní. En su discurso manifestó a la importancia rescatar este sistema productivo tradicional que proveerá al mercado de un producto diferenciado del resto, de una calidad especial muy superior a la del común de las yerbas. Los barbacuás ya no eran una algo obsoleto sino la llave para alcanzar una producción diferenciada con precios superiores en el mercado.

\section{La red socio técnica inconclusa: Logros y faltantes de un proceso de traducción}

En el presente artículo hemos considerado la experiencia de la "Asociación de Productores en Sistema Barbacuá" prestando atención al desarrollo histórico de la actividad yerbatera así como a aspectos estructurales de la misma. La perspectiva del actor-red permite iluminar la rearticulación de una red socio-técnica en torno a un actante casi desechado por la industrialización de la actividad yerbatera: el barbacuá. En efecto, la producción, elaboración y consumo de la yerba mate se desarrolla en esta red de modo diferente a lo establecido por los actores más concentrados. Los productores familiares pueden hacer valer sus conocimientos de generaciones sobre su actividad, elaborar su propia materia prima y ofrecer a distribuidores y consumidores un producto de superior y diferenciado del promedio de la industria. La red así constituida incluye pequeñas plantaciones, genera empleo en las colonias y brinda una alternativa a los productores familiares que integran la asociación.

El proceso de traducción entablado por los ingenieros del INTA junto a los productores de la asociación ha realizado notables avances como se ha señalado en este artículo. Sus limitaciones o faltantes se registran en el interesamiento y enrolamiento de actores vinculados a las etapas de la comercialización y el consumo. La comercialización de la yerba mate producida por los miembros de la asociación implica articular redes fundamentalmente distintas a las de las grandes marcas industriales. Debido a manejar volúmenes pequeños no es viable su ingreso a cadenas de supermercados y otros actores centrales de la comercialización de alimentos. Las marcas existentes apelan a la venta en las ferias francas de productores que se realizan

\footnotetext{
${ }^{2}$ Se trata de los Ingenieros Luis Bárbaro y Osvaldo Sforza de la Agencia de Extensión Rural de Oberá del INTA.
} 
en localidades de la provincia de Misiones y a unas pocas cooperativas de comercialización y consumo de grandes centros urbanos. Eventualmente logran vender pequeñas cantidades a consumidores y comercios minoristas distantes a través de envíos. En el año 2012 los miembros de la asociación inician los trámites ante el INAES (Instituto Nacional de Acción Cooperativa) para la creación una cooperativa con el fin de poder sacar al mercado una marca colectiva con producción de de todos ellos. Aunque esta tramitación aún no ha concluido en 2015, el intendente de la localidad de Guaraní ya les ha facilitado un predio para la instalación de un molino.

Ciertamente se trata de un proceso de traducción inconclusa o más bien imperfecta pues siguen existiendo dificultades importantes en la etapa de comercialización y consumo de la red socio técnica aquí considerada. Otro desafíos que enfrenta esta red es que una de las grandes empresas del sector sacó recientemente al mercado una yerba de calidad superior producida en sistema barbacuá cuya producción es realizada por diferentes productores de la región, incluyendo a uno de los miembros de la cooperativa. Los actores más concentrados cuentan con el poder de desinteresar a productores de la asociación o de prevenir el ingreso de otros en el futuro, así como de disputarle un potencial nicho de mercado que puede generar la yerba barbacuá. En este sentido, sería estratégico para los miembros de la asociación lograr interesar y enrolar a consumidores a fin de que no solamente valoren la yerba de secadero barbacuá y estacionamiento prolongado sino que también que se trata de productores familiares preservando un sistema productivo con una larga historia en el territorio.

La perspectiva teórica adoptada por este trabajo de investigación ha resultado adecuada para el caso considerado. La teoría del actor red destaca que si queremos comprender los procesos por los cuales una red socio técnica emerge y se expande, no debemos limitarnos a una perspectiva, ya sea económica, política o social, sino más bien tratar de comprender como todos estos elementos se combinan en la invención de la red en cuestión. La traducción implica un proceso de invención en el que se crean conexiones entre entidades heterogéneas que a su vez modifican a estas. El caso de la asociación de productores en sistema barbacuá permite apreciar como la recuperación y mejoramiento de un artefacto que encierra siglos de historia de la región y de la producción de yerba mate hace posible redefinir o en los términos de la teoría del actor red "re inventar" una red socio técnica.

Más allá de las limitaciones o debilidades de la red socio técnica constituida. Debe destacarse que la iniciativa de los ingenieros del INTA permitió a través de la recuperación y potenciación de un modo de una tecnología tradicional como la del barbacuá generar una alternativa a la concentración de industria y una alternativa productiva para los productores familiares considerados. El tiempo, las estrategias que puedan seguir desplegando y la voluntad de los que impulsan esta red socio técnica tendrán la última palabra.

\section{BIBLIOGRAFÍA}

BOLSI, A. "El primer siglo de economía yerbatera en Argentina", Folia Histórica del Nordeste, $\mathrm{n}^{\circ}$ 4. Resistencia-Corrientes: Instituto de Historia, Facultad de Humanidades, Universidad Nacional de Nordeste. 1980.

BOLSI, A. "Misiones. Una aproximación geográfica al problema de la yerba mate y sus efectos en la ocupación del espacio y el poblamiento", Folia Histórica del Nordeste $\mathrm{n}^{\mathbf{0}} 7$. Resistencia: Instituto de Historia, Facultad de Humanidades, Universidad Nacional de Nordeste. 1986. 
BUEGER, Christian y Jan Stockbruegger (en prensa) "Actor-Network Theory: Objects and Actants, Networks and Narratives" en For Technology and World Politics: An Introduction, edited by Daniel R. McCarthy, Abingdon: Routledge.

CAFFERATA, A.; C. De Santos y G. Tesoriero (1974), Formación y desarrollo de las estructuras agrarias regionales: Misiones y Formosa, Buenos Aires, CFI.

CALLON, M. "Éléments pour une sociologie de la traduction, la domestication des coquilles Saint-Jacques et des marins-pêcheurs dans la baie de Saint-Brieuc", L'année sociologique, 36, p. 169-208, 1986a.

CALLON, M. "The Sociology of an Actor-Network: The Case of the electric vehicle" M.Callon, J. Law y A.Rip Mapping the Dynamics of Science and Technology. Sociology of Science in the Real World, London: MacMillan Press. p 19-34, $1986 \mathrm{~b}$.

DAZA VILLADIEGO, C. (2012) "Modelo de efectividad de la red de Innovación Tecnológica", Undécima Conferencia Iberoamericana en Sistemas, Cibernética e Informática: CISCI 2012, Orlando, EE.UU. Capturado en <http://www.iiis.org/CDs2012/CD2012SCI/CISCI_2012/PapersPdf/CA229KF.pdf >. Acceso: 01 jul. 2015)

DO SANTOS, V. Problemática de Sistemas Productivos Tradicionales: Abordaje Sociológico de Secaderos Barbacuá en las colonias de Zona Centro de la Provincia de Misiones orientados al Turismo, Monografía de grado, Departamento de Turismo, Facultad de Humanidades y Ciencias Sociales, Universidad Nacional de Misiones, 2013.

GORTARI, J. "La yerba mate: un rito guaraní de proyección universal», en J. Gortari (comp.), De la tierra sin mal al tractorazo. Hacia una economía política de la yerba mate, Posadas: Editorial Universitaria de Misiones, 2007a.

GORTARI, J. "Algunos desarrollos teóricos para el análisis de la problemática yerbatera", en J. Gortari (comp.) De la tierra sin mal al tractorazo. Hacia una economía política de la yerba mate, Posadas: Editorial Universitaria de Misiones, $2007 b$.

GORTARI, J. "El Instituto Nacional de la Yerba Mate (INYM) como dispositivo político de economía social" en Javier Gortari (comp.) De la tierra sin mal al tractorazo. Hacia una economía política de la yerba mate, Posadas: Editorial Universitaria de Misiones, 2007c.

LARGUIA, A. Misiones - Itapúa y los pioneros del oro verde. Buenos Aires: Corregidor, 2006.

LAW, J., "On the methods of long-distance control: Vessels, navigation and the Portuguese route to India", en Law, J. (ed.), Power, Action and Belief: A New Sociology of Knowledge, Londres, Routledge and Kegan Paul, p. 234-263, 1986.

LOPEZ, A. "The Economics of yerba mate in Seventeenth-Century South America", Agricultural History, vol. 48, No. 4, p. 493-509, 1974. 
RICCA, J. El Mate. Historias secretos y otras yerbas de una pasión rioplatense. Buenos Aires: Editorial Sudamericana, 2002.

RAU, V. "La yerba mate en Misiones (Argentina). Estructura y significados de una producción localizada", Agroalimentaria, n. 28, Enero-Junio, p. 49-58, Venezuela: Universidad de los Andes, 2009.

SHIGA, J. "Translations: Artifacts from an Actor-Network Perspective", Artifact, Vol. I, Issue 1, p. 40-55, Indiana University, 2007

RAU, V. Cosechando yerba mate. Estructuras sociales de un mercado laboral agrario en el Nordeste argentino. Buenos Aires: CICCUS, 2012.

VIDAL DE BATTINI, B. "El léxico de los yerbateros", Nueva Revista de Filología Hispánica, Año 7, no. 1-2. México: El Colegio de México. 1953. p 190-208

WALSH, R. (1966) "La Argentina ya no toma mate" en Javier Gortari, De la tierra sin mal al tractorazo. Hacia una economía política de la yerba mate, Posadas: Editorial Universitaria de Misiones.

"La yerba mate" Comisión reguladora de la producción y comercio de la yerba mate. 1971. Capturado en:

$<$ http://elmuseodelmate.com.ar/index.php?option=com_content\&view=article\&id=56:or igen-de-la-yerbamate\&catid=34:articulos\&Itemid=53>. Acceso: 18 abr. 2015.

Ministerio del Agro y la Producción de la Provincia de Misiones - INTI, "Convenio Específico Asistencia Técnica", 7 de Noviembre de 2013. Capturado en: <http://www.inti.gob.ar/pdf/convenios2013/especifico_asis_tecnica_misiones.pdfhttp:// www.inti.gob.ar/pdf/convenios2013/especifico_asis_tecnica_misiones.pdf $>$. Acceso: 31 maio 2015.

Submetido em 01/02/2016

Aprovado em 30/05/2016

\section{Sobre o autor}

Pablo Fourni

M.A. en Sociología. PhD en Sociología. CONICET

E-mail: forni@retina.ar 